Price Discovery, Cross-listings and Exchange Rates: Evidence from Australia and New Zealand

\author{
Bart Frijns* \\ Nijmegen School of Management \\ Radboud University Nijmegen \\ P.O. Box 9108, 6500 HK Nijmegen, The Netherlands
}

Email: $\underline{\text { b.frijns@fm.ru.nl }}$

\author{
Aaron Gilbert \\ Department of Finance \\ Auckland University of Technology \\ Private Bag 92006, 1020 Auckland, New Zealand \\ Email: agilbert@aut.ac.nz
}

\author{
Alireza Tourani-Rad \\ Department of Finance \\ Auckland University of Technology \\ Private Bag 92006, 1020 Auckland, New Zealand \\ Email: atourani@aut.ac.nz
}

* Corresponding Author 


\title{
Price Discovery, Cross-listings and Exchange Rates: Evidence from Australia and New Zealand
}

\begin{abstract}
This paper examines price discovery for four Australian stocks cross-listed in New Zealand and five New Zealand stocks cross-listed in Australia for the period January 2002 to December 2005. Estimating Hasbrouck (1995) information shares over time reveals that the importance of the Australian market is growing. However, when incorporating the AUD/NZD cross-rate into the model, we find that this growing importance disappears. The reason for this is that both the Australian and the New Zealand currencies are so-called "commodity currencies" and are therefore not exogenous with respect to stock prices. We find that the shift in price discovery can be explained by a shift in the relative role of both markets in the determination of the cross-rate. Implications of this study are that when studying similar countries, the exchange rate cannot be considered as an exogenous process.
\end{abstract}

Key Words: Price Discovery, cross-listings, exchange rates, market microstructure.

JEL-Codes: C32, G15.

EFM- Codes: 360, 610. 


\section{Introduction}

When a single asset is cross-listed on different foreign markets an important question that arises is how informative each market is about that asset's price. In the market microstructure literature this topic is known as price discovery (see e.g. Hasbrouck, 1995). The study of price discovery relies on the implicit assumption that price differentials between markets are bounded due to arbitrage opportunities. Such price differentials can only be measured when prices are observed in each market. For this reason, the study is typically conducted for the period when trading hours of the different markets overlap (e.g. Eun and Sabherwal 2003 and Pascual et al. 2006). ${ }^{1}$ More than that, most studies have focused on cross-listings of non-US firms that list their shares, or derivatives thereof (ADRs, etc.), in the US. With the exception of a few studies, the overlap in trading hours is generally small, which renders conclusions about the informational roles of the different markets incomplete. Therefore assessing price discovery for markets with a larger overlapping period may provide a more complete picture of the informational role of both markets.

An important issue put forward by Grammig et al. (2005) is that the informational role of different markets can be better assessed when the exchange rate is incorporated into the price discovery model. By incorporating the exchange rate into this model, one can assess to which extent each market incorporates the exchange rate changes. Furthermore, ignoring the exchange rate could lead to wrong conclusions about price discovery. A market may be considered an informational satellite in terms of price discovery, while in fact this market only adjusts for exchange rate changes. This would especially hold for countries with so called "commodity currencies" (see Chen and Rogoff, 2003), where the exchange rate is not an exogenous process.

In this paper we assess price discovery for cross-listed stocks between two markets, the Australian Stock Exchange (ASX) and the New Zealand Stock Exchange (NZX), that share a large overlap in trading hours (under normal circumstances five hours). Besides having a large overlap in trading hours, these markets also cross-list shares in each others markets, i.e. Australian shares have cross-listings in New Zealand and

\footnotetext{
${ }^{1}$ An exception to this is Menkveld et al. (2006) who study price discovery for Dutch shares cross-listed in the US for the overlapping, non-overlapping and non-trading hours.
} 
vice versa. This provides an excellent opportunity to assess whether for these bidirectional cross-listings the home market remains dominant as found by studies that consider uni-directional cross-listings (e.g. Pascual et al., 2006 and So ad Chong, 2006).

To assess price discovery for these cross-listed stocks we follow two approaches. Firstly, we compute information shares as suggested by Hasbrouck (1995) over a long period of time (January 2002 to December 2005) and over one year sub-periods to examine the change in price discovery over time. Secondly, we incorporate the exchange rate as suggested by Grammig et al. (2005) to assess the role of the exchange rate in the price discovery process.

The price discovery analysis for these cross-listed stocks leads to some interesting findings. Firstly, in line with previous research (e.g. Grammig et al., 2005 and Pascual et al., 2006) we find that home markets remain dominant in terms of price discovery, both when prices are converted into a single currency and incorporating the exchange rate in the model. When assessing price discovery over time in a single currency we find that for both Australian and New Zealand domiciled stocks the information share for the ASX increases. However, when we incorporate the exchange rate we find that this increase disappears. The difference in findings is likely a result of the fact that ASX and NZX prices play an informational role in the determination of the exchange rate. As described by Chen and Rogoff (2003) the Australian and New Zealand currencies are so-called "commodity currencies", where relative commodity prices in both countries affect the dynamics of the cross-rate. Hence in order to assess price discovery in these markets, we cannot ignore the exchange rate and simply convert stock prices into a single currency. This finding is important as it may similarly affect the price discovery process in other countries.

The remainder of this paper is organized as follows. In the next session we discuss some of the relevant literature on price discovery among cross-listed shares. Section 3 describes the Hasbrouck (1995) information share and Grammig et al.'s (2005) extension to this. In Section 4 we present the data and show some summary statistics. Section 5 presents the results of the model and finally section 6 concludes. 


\section{Literature Review}

The question of price discovery has been examined in a variety of market settings and asset classes. One question of particular interest has been on the dynamics of assets listed on multiple markets. The dramatic increase in the number of companies cross listed on foreign exchanges in recent times, has made it both necessary and important to consider where information is impounded into prices (e.g. Eun and Sabherwal, 2003).

The examination of price discovery for companies listed in multiple markets started by examining the roles of US regional stock exchanges and the NYSE in impounding information into prices. Harris, McInish, Shoesmith and Wood (1995), for instance, examine the price discovery of IBM on the NYSE and two other regional exchanges and found that all three markets played an important role in the price discovery of that stock. Hasbrouck (1995) went further and defined a measure of the relative importance of the various markets' contribution to price discovery, the information share. Based on a sample of 30 DJIA companies, Hasbrouck shows that NYSE price changes represented $92.7 \%$ of the price discovery with regional exchanges making up the remainder. More recently, Harris, McInish and Wood (2002) examined the importance of the NYSE in comparison to regional exchanges over time. While they show that for the most part the NYSE has remained the dominant information market, this has declined and regional exchanges as late as 1995 contributed nearly $40 \%$ of the price discovery, while representing only $16 \%$ of the trading volume. This indicates that the regional exchanges in the US play an important informational role.

While the examination of price discovery on multiple markets started with domestic firms in the US, more recent work has also focused on firms with listings in different countries. In general, the findings of this literature indicate that price discovery predominantly occurs in the home market, with the prices in the foreign market mainly adjusting to the prices in the home market. For instance Su and Chong (2006) find that for eight Chinese firms listed on both the Hong Kong Stock Exchange (SEHK) and the NYSE the average information share was $89.4 \%$ for the SEHK market. Xu and Fung (2002), examining the same market, also found that the majority 
of information transmission came from the home market (SEHK), while the foreign market (NYSE) was predominantly responsible for volatility spillover. Lieberman, Ben-Zion and Hauser (1999) observe that for a sample of 6 Israeli firms the majority of the price discovery occurs in Israel for all but 1 firm, with the NYSE contributing only a small amount. These studies reveal a limited but not negligible role for the NYSE.

There is, however, there is some variation in the relative informational roles of the home and foreign markets in the literature. For instance, while the previously discussed studies conclude that the foreign market has an informational role, Pascual, Pascual-Fuster and Climent (2006) find that the influence of the NYSE on a sample of 5 Spanish stocks was insignificant. This supports Grammig et al. (2005) who come to a similar conclusion for a sample of three German stocks cross-listed on the NYSE. On the other side of the spectrum are studies that do find important roles for the foreign market. Hupperets and Menkveld (2000), for example, find that Dutch stocks cross-listed on the NYSE have wide variations in price discovery with some stocks predominantly driven by the Amsterdam market, while others are driven by the NYSE and some are driven by both. Likewise, Kadapakkam, Misra and Tse (2003) observe that for Indian companies cross-listed on the London Stock Exchange each market contributes on average nearly equally to price discovery. Eun and Sabherwal (2003) aim to explain the variation they found in their examination of the price discovery of Toronto Stock Exchange stocks cross-listed on US exchanges. They observed variations in the percentage of price discovery occurring on US exchanges ranging from 0.02 to 98.2 with an average of $38 \%$. Using regression analysis, they found a positive relationship between price discovery and the ratio of proportions of information trades occurring in the US. This is consistent with the observations of Lieberman et al. (1999) and Hasbrouck (1995). They also found a negative relationship with the ratio of bid-ask spreads, i.e. high spreads relate to a low degree of price discovery.

What is notable in the literature is that it is predominantly focused on the price discovery of foreign issues on the major exchanges, in particular the US market. Very few studies have considered situations where the foreign market is a smaller exchange. An example, for instance, is Ding, Harris, Lau and McInish (1999) who 
consider the case of a Malaysian conglomerate cross-listed on the Stock Exchange of Singapore. In line with the literature they find that nearly $70 \%$ of the price discovery occurs in the home market. Another example, related to this study is Lok and Kalev (2005) who consider New Zealand and Australian cross-listings. Using an errorcorrection model, they find that prices in the foreign market error correct mostly to price in the home market, while there is only a limited error correction of home market prices to foreign prices. However, they do not assess price discovery explicitly by comparing measures for price discovery across markets. Beyond this, little research has considered situations outside the US.

A second issue that has been widely overlooked in the literature is the role of exchange rates. Most studies treat exchange rates as exogenous factors, converting all prices into a common currency before testing for price discovery. For instance, Lieberman et al. (1999) converts the Israeli prices into US dollars while Eun and Sabherwal (2003) convert US prices into Canadian prices. However, as Grammig et al. (2005) point out, there is little prior evidence that suggests how stock prices in multiple markets adjust to exchange rate changes. They therefore examine the impact of exchange rate changes on price discovery for a selection of German companies traded on both XETRA and the NYSE, using a modified measure of the Hasbrouck (1995) information share, which incorporates the exchange rate. Consistent with previous studies they observe that most of the price discovery occurred in the home market. They also find that the prices in the foreign market fully adjust to incorporate the changes in the exchange rate, with no adjustment in the XETRA prices. Finally, they conclude that models that exclude the exchange rate, bias the information share of the market whose price is converted. The degree of bias is related to the level of exchange rate bias in the market. In this paper we will evaluate the role of the exchange rate for Australian and New Zealand cross-listed stocks.

\section{Methodology}

In this section we discuss the measure for price discovery used in this paper, the Information Share (IS) as introduced by Hasbrouck (1995). The measure considers the contribution of each market to the total variance of the price process. We further 
discuss an extension to this measure proposed by Grammig et al. (2005) which endogenizes the exchange rate.

\subsection{The Hasbrouck (1995) Information Share}

The IS relies on the assumption that when a security is cross-listed in different markets, the prices in these markets share one common trend, i.e. prices are cointegrated. Let $p_{t}^{h}$ be the $\log$ price of an asset in the home market in local currency. Likewise, define $p_{t}^{f}$ as the $\log$ price of the asset in the foreign market expressed in the same currency as $p_{t}^{h}$. Arbitrage implies that prices can never diverge without bounds

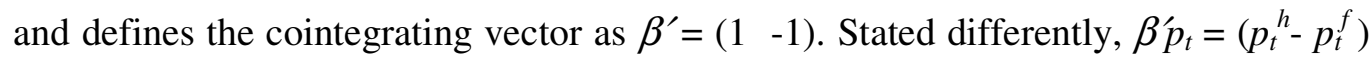

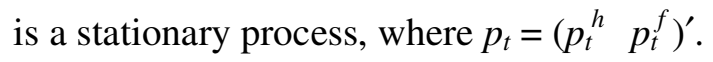

The fact that the prices are cointegrated implies that the dynamics of price changes in both markets can be described by an error correction model of the form

$$
\Delta p_{t}=c+\alpha \beta^{\prime} p_{t-1}+\sum_{i=1}^{N} \gamma_{i} \Delta p_{t-i}+\varepsilon_{t}
$$

where $c$ is a $(2 \times 1)$ vector of constants, $\alpha$ is a $(2 \times 1)$ vector which measures the speed of adjustment to the error correction term and $\gamma_{i}$ are $(2 \times 2)$ matrices of AR coefficients. A key determinant for the study of price discovery is $\alpha$, the speed of adjustment to the error correction term. When a market dominates in terms of price discovery, its value in the $\alpha$-vector will be small, indicating that this market does not correct to any differences in prices between markets. When a market is a satellite market, its element in $\alpha$ will be large relative to the dominant market, indicating strong adjustment to the error in prices.

To define the Hasbrouck (1995) information share we rewrite (1) in its Wold reprentation, i.e.

$$
\Delta p_{t}=\Psi(L) \varepsilon_{t},
$$


where $\Psi(L)$ is a matrix polynomial in the lag operator. Following Beveridge and Nelson (1981) we can decompose $\Psi(L)$ into two components and write (2) as

$$
\Delta p_{t}=\Psi(1) \varepsilon_{t}+(1-L) \Psi^{*}(L) \varepsilon_{t}
$$

where $\Psi(1)$ is the sum of all moving average coefficients $\left(\Psi(1)=\mathrm{I}+\Psi_{1}+\Psi_{2}+\ldots\right)$ and $\Psi^{*}(L)$ is a second matrix polynomial. Stationarity implies that $\Psi(1)$ is finite. Integrating (3) also defines the log price process, i.e.

$$
p_{t}=\Psi(1) \sum_{s=1}^{t} \varepsilon_{s}+\Psi^{*}(L) \varepsilon_{t} .
$$

Since $\Psi(1)$ is finite, it measures the long-run impact of a shock to the level of prices, and the value of its elements can be found by computing the impulse response functions for the integrated model of (1).

The information share as defined by Hasbrouck (1995) follows from the variance decomposition of (3). Since $\beta^{\prime} p_{t}$ is a stationary process, $\beta^{\prime} \Psi(1)=0$ which, given the definition of $\beta$, implies that the rows in $\Psi(1)$ are identical. Defining one row of $\Psi(1)$ as $\psi$, the information share, defined as the proportion of variance of the price process attributable to each market, for market $j$ is defined as

$$
I S_{j}=\frac{\psi_{j} C_{j j}}{\psi \Omega \psi^{\prime}},
$$

where $\Omega=\operatorname{Var}\left(\varepsilon_{t}\right)$ and $C$ is the lower triangular Choleski factorization of $\Omega$ (i.e. $\Omega=$ $C C^{\prime}$ ). This Choleski factorization needs to be applied because $\Omega$ is typically not a diagonal matrix. When taking only the elements on the diagonal of $\Omega$ in the computation of IS, we ignore the fact that part of the variance in market $j$ may be caused by the variance in the other market, i.e. there may be a contemporaneous common component or spillover in the variance of market $j$. By applying a Choleski decomposition to $\Omega$ we orthogonalize the innovation terms $\varepsilon_{t}$, by assigning all the common variance to e.g. market $j$. However, since we do not know which market is 
the source of this common variance, we cannot assign all the common variance to one market. Therefore we need to permute over all possible orderings of $\varepsilon_{t}$, with the consequence that we can only obtain a range of information shares and not a unique value for each market. ${ }^{2}$

\subsection{Endogenizing the Exchange rate}

Grammig et al. (2005) note that an understudied issue in the price discovery literature for cross-listed stocks is the effect of exchange rate changes on asset prices in both markets. They extend the Hasbrouck's (1995) model by including the exchange rate. Below, we briefly discuss this extension.

Similar to the situation before we consider an asset listed in home and foreign market. Let $p_{t}^{h}$ be the $\log$ price of the asset in the home market in local currency, $p_{t}^{f^{*}}$ be the $\log$ price of the asset in the foreign market in foreign currency and $e_{t}$ be the $\log$ exchange rate between home and foreign market. Prices are again cointegrated because $\left(p_{t}^{h}-p_{t}^{f^{*}}+e_{t}\right)$ is a covariance stationary process. Hence, the process for price changes can again be described by an error correction model, and $\Psi(1)$ can be estimated as before. However, the fact that there is one cointegrating relationship between three price series implies two different underlying random walk processes (one for the prices of the assets and one for the exchange rate). This means that the rows of $\Psi(1)$ are not identical. Stated differently, we cannot compute a single information share for each price series as before. Grammig et al. (2005) therefore suggest computing information shares per market. For instance, we can compute the information share of the exchange rate, home and foreign market in the home market. We therefore obtain information shares for each market, which we refer to as conditional information shares (CIS). The conditional information share of market $k$ with respect to market $j$ is computed as

$$
C I S_{j k}=\frac{\left([\Psi(1) C]_{j k}\right)^{2}}{\left(\Psi(1) \Omega \Psi(1)^{\prime}\right)_{j j}}
$$

\footnotetext{
${ }^{2}$ Hasbrouck (1995) reports both upper and lower bounds obtained in the Choleski decomposition. Alternatively, Booth et al. (2002) suggest using the midpoint of the information share as a single measure of price discovery.
} 
This measure again depends on the specific ordering of $\varepsilon_{t}$ and we need to permute over all possible orderings to establish upper and lower bounds.

\section{Data}

Our study considers both Australian and New Zealand domiciled companies that cross-list shares in each others markets. Since accurate estimation of information shares can only be achieved when data is sampled at very high frequencies, we need to restrict our sample to the most liquid companies trading on the ASX and the NZX. The sample we select therefore consists of four Australian domiciled firms (Australian Mutual Provident Society (AMP), Australia and New Zealand Banking Group (ANZ), Lion Nathan (LNN), Telstra (TLS)) and five New Zealand domiciled firms (Auckland International Airport (AIA), Telecom (TEL), the Warehouse (WHS), Tower (TWR), Fletcher Building (FBU)) that are traded on both the ASX and NZX. These stocks are selected because they offer sufficient liquidity in both markets.

Intraday data for these firms as well as the intraday NZD/AUD exchange rate data are obtained from SIRCA (Securities Industry Research Centre of Asia-Pacific). The data for stocks on both markets includes trade and quote data. The trade data includes time of trade, trade price, trade volume, and the standing bid and ask quotes at the time of trade with their associated volumes. The quote data contains the time a quote is innovated, the bid and ask quote and the volumes quoted on each side of the market. The exchange rate data only contains data on quotes, being time of the quote issued, the bid and ask price and associated volumes. We collect this data for a long time period to allow us to look at the evolution of the information share over time. Specifically, we examine a four year period running from 1 January 2002 to 31 December 2005, excluding those days where there was no trading on one or the other market.

Given the small difference in time zones (normally two hours between New Zealand and New South Wales where the ASX is based) there is a long period of overlap. The ASX operates normal trading each day from 10 am AEST until 4 pm while the NZX operates normal trading from 10 am NZ time until $5 \mathrm{pm}$. The overlapping period therefore runs from the start of normal trading on the ASX until the end of trading on 
the NZX. For most of the year this results in 5 hours of overlapping operation between the two markets. However, due to differences in the start and end dates of Daylight Savings this overlap can range from 4 hours to 6 hours. The exchange rate also had to be adjusted for differences in time zones as it was based on GMT. Since the exchange rate market lists quotes 24 hours a day it imposed no restriction on the overlapping period.

\section{INSERT TABLE 1 HERE}

In Table 1 we present summary statistics for the selected stocks for the whole sample period. The summary statistics are computed considering the overlapping period only. We report trade statistics as well as quote statistics. For the Australian domiciled firms we find that the trading activity of these firms is much higher on the ASX, both in terms of trading frequency and trading volumes. The most liquid firm, TLS, trades on average 1249 times a day in the ASX, opposed to only 10.6 times per day on the NZX. The same is observed in trading volumes. About 13,617,000 shares are traded daily on the ASX whereas only 77,087 shares are traded daily on the NZX. The same observation can be made from the quote statistics. On average more quotes are issued on the ASX relative to the number of quotes issued on the NZX. Interestingly, this is also seen in the respective bid-ask spread, which are considerably wider on the NZX than on the ASX. All these statistics indicate that for the Australian domiciled firms, trading and quoting activity is dominated on the ASX.

For the New Zealand domiciled firms the findings are similar, though less pronounced than for the Australian domiciled firms. We find that for most firms trading activity and volume is higher on the NZX, although the trading activity for TEL and TWR is similar on both markets. Also when turning to the quote statistics, findings are similar to those for Australian domiciled firms, except for the stocks of TEL and TWR.

The results presented above indicate that most of the trading and quoting activity of the cross-listed shares remains in their market of domicile. However, to formerly analyze whether the home market is also the most important in terms of price discovery we need to assess the informational role of each market. 
In order to study the issue of price discovery we follow Grammig et al. (2005) by considering quotes instead of trades. That is, to estimate the information shares the midpoint of the most recent bid and ask quotes will be used. Using the midpoint of bid and ask quotes mitigates the impact of microstructure noise. Since the stocks traded on the ASX and NZX are substantially less liquid than shares listed on the NYSE for instance, the bid-ask spread tends to be wide. The resulting large bid-ask bounce could be an issue therefore transaction prices were to be used. We aggregate data for each market and for the exchange rate to a one minute frequency and consecutively merge the data for the overlapping trading periods.

\section{Results}

In this section the results for the models proposed in section 3 are presented. We first report results for the model where all prices are in Australian dollars. Second, we consider prices in their own domestic currencies and incorporate the exchange rate following Grammig et al. (2005).

\subsection{Hasbrouck Information Shares}

The first step in the analysis of price discovery is to check whether prices are cointegrated. We do this by performing Johansen's (1988) test for cointegation. In this test we determine the optimal lag length using the Schwarz Information Criterion (SIC) and estimate the unrestricted and restricted VARs excluding the first $n$ observations of each day, where $n$ is the number of lags determined by the SIC. These observations are excluded to ensure that the coefficients for the AR components do not reflect overnight changes in prices. The Johansen test confirms that the hypothesis of no cointegrating relationship is strongly rejected (at the $1 \%$ level). Tests further show that we cannot reject the hypothesis of at least one cointegrating relationship. Cointegrating vectors are found to be close to the theoretically expected relationship. ${ }^{3}$

Next, we estimate the error correction model for all stocks in the sample for the full sample period using the theoretical cointegrating vector $\beta=(1-1)$. Given the parameter estimates of the VECM, we compute $\Psi(1)$ using impulse response

\footnotetext{
${ }^{3}$ Results for the cointegration tests are not reported, but are available upon request.
} 
functions. To ensure convergence of the long-run impact of a unit shock, we compute impulse responses for 5000 steps ahead. Using the elements of $\Psi(1)$ we can compute the information shares for the various stocks.

\section{INSERT TABLE 2 HERE}

In Table 2 we report the upper and lower bounds, and midpoints for the information shares for the stocks in our sample. In line with findings of previous studies (e.g. So and Chung, 2006, and Lieberman et al., 1999) we observe that price discovery mainly takes place in the home market for each stock. For Australian domiciled firms (except for AMP), most of the price discovery takes place in the home market. However, the informational role of the NZX is not negligible. This finding is in line with the results reported in Table 1, which show that most of the trading and quoting activity takes place on the ASX and spreads are smallest. This confirms the relationship between information shares and measures of liquidity as suggested by Eun and Sabherwal (2003). An interesting case is AMP as liquidity is higher on the ASX, while price discovery is dominated by the NZX.

For New Zealand based stocks similar results are found. The midpoint of information share for the home market ranges from $81.41 \%$ to $95.33 \%$. Interestingly, the NZX is by far the dominant market for TEL and TWR, whereas Table 1 indicated that both market participated equally in the trading and quoting process for these shares. We also observe that for all stocks the range between the upper and lower bound is relatively narrow, indicating that contemporaneous correlation does not pose a serious problem at the 1 minute sampling frequency. Also, upper and lower bounds for ASX and NZX do not overlap.

As a second investigation we consider how these information shares have changed over time. Therefore the midpoint of information shares each year is computed by estimating the VECM annually. The results of this analysis are reported in Table 3.

\section{INSERT TABLE 3 HERE}


There are several interesting findings in this table. When considering the Australian domiciled firms, we find that over time the information shares in New Zealand decrease (except in the case of ANZ). This indicates a diminishing importance of the NZX for Australian domiciled companies. On the other hand, when the New Zealand based companies are examined, we find that the information shares for the ASX increase, indicating the Australian market has become more important for New Zealand cross-listed firms. Given that this trend is present for stocks from both markets, it appears the ASX is growing in importance relative to the NZX. Lastly, the high NZX information share for AMP observed in Table 2 almost completely disappears when studying information shares on an annual basis and it seems that this result was mainly caused by the high NZX information share found in 2003.

The results for information shares are mostly in line with previous literature which suggests a dominant role for the home market of shares. In addition there appears to be an increasing importance of the ASX in terms of price discovery.

\subsection{Endogenizing the Exchange Rate: Impulse Response Functions}

As a second analysis we endogenize the exchange rate in the VECM and compute conditional information shares per market as suggested by Grammig et al. (2005). We again start by evaluating whether cointegrating relationships are present among the price series. The Johansen tests again reject the null hypothesis of no cointegrating relationship and in most cases find evidence for one cointegrating relationship among the three variables. ${ }^{4}$ Estimated cointegrating vectors are again very close to the theoretical hypothesized cointegrating vectors and this theoretical relationship is used as the cointegrating vector in the VECM.

After estimating the VECM we again compute impulse response functions to determine the long-run impact matrix $\Psi(1)$ (elements in $\Psi(1)$ are estimated by computing impulse responses of 5000 steps ahead). In Figure 1 we show the results for the impulse response functions for up to 2000 steps ahead. We first discuss plots for Australian based firms and subsequently discuss results for New Zealand based firms.

\footnotetext{
${ }^{4}$ Results are again available on request.
} 


\section{INSERT FIGURE 1 HERE}

The first column of Panel A shows plots of the impulse response functions where a unit shock is applied to the exchange rate. In line with the results presented before, we find that for Australian based companies most of the exchange rate shock is incorporated into the New Zealand prices. However, for most stocks (most pronounced for AMP) there is also an adjustment in Australian prices. This contrasts Grammig et al. (2005) who find that the adjustment to exchange rate shocks is only observed in the foreign market. When shocks to the Australian prices (second column) are considered some interesting results emerge. First, these shocks are persistent and lead to a strong adjustment in the New Zealand prices. This is in line with previous reported results of the ASX being the dominant market for these securities. Second, although being smaller than the impact of Australian price shocks on New Zealand prices, shocks to Australian prices also lead to an adjustment in the exchange rate. This result contrasts the findings of Grammig et al. (2005), who find that the exchange rate is exogenous to shock is the prices of the stock markets and may be a specific feature of these two markets. The last column shows the impulse response functions for shocks applied to the New Zealand prices. The impact of these shocks is minimal (except for AMP), indicating that the NZX can be considered a satellite market. Again we again we observe that shocks to New Zealand prices have an impact on the exchange rate, although the impact is smaller than for the shocks to Australian prices.

In panel B of Figure 1 we present the impulse response functions for New Zealand domiciled firms. When considering shocks to the exchange rate almost all of the correction for the exchange rate shock occurs in the Australian market. Combined with the findings for the Australian domiciled companies this shows that the correction for the exchange rate shocks mainly occurs in the foreign market. When applying shocks to the Australian prices (column 2), we observe that these shocks have almost no impact on the levels of prices in New Zealand. However, as we observed before, the exchange rate adjusts in some degree to shocks in Australian

prices. When shocks are applied to New Zealand prices (last column), these shocks are persistent and results in a strong adjustment in the Australian prices towards the 
New Zealand prices. Again these shocks have an impact on the exchange rates, but to a lesser extent then shocks in Australian prices.

The fact that shocks to both markets have an impact on the exchange rate poses an interesting puzzle. As Grammig et al. (2005) mention, the exchange rate is expected to be exogenous with respect to home and foreign stock markets as the exchange rate

dynamics are determined by other factors. However, the markets considered in this study are distinctly different from those studied by Grammig et al., as is the foreign exchange market in the AUD/NZD as compared to the USD/EURO. The AUD/NZD cross-rate is often referred to as a "commodity currency" (Chen and Rogoff, 2003) as its rate is strongly influenced by the relative changes in commodity prices in both markets. Interestingly, when comparing columns two and three for both panels we observe that shocks to Australian prices of securities (be it Australian or New Zealand based) have a much more persistent impact on the exchange rate than shocks applied to New Zealand prices of securities. For such markets it is therefore important to endogenize the FX rate into the model.

\subsection{Conditional Information Shares}

The next step in our analysis is to compute the conditional information shares per market. These conditional information shares can be interpreted as the information share of market $\mathrm{X}$ in market $\mathrm{Y}$. In Table 4 we report these information shares.

\section{INSERT TABLE 4 HERE}

In Panel A the results for the Australian domiciled firms are reported. The addition of the exchange rate in the model reveals several notable points. In line with Table 2, we find that the ASX is the dominant market for both LNN and TLS. The conditional information shares reveal that this dominance is manifested in both ASX and NZX. Similarly, for AMP the NZX is dominant both in determining prices on the NZX and the ASX. An interesting case is ANZ. Table 2 revealed that for ANZ the ASX was the dominant market. However, when we consider the conditional information shares we find that the high ASX information share is only observed in the Australian market. In the New Zealand market, the information shares for ASX and NZX are much closer to 
each other, leading us to conclude that the NZX prices are important for the price discovery in the New Zealand market.

When considering the last column the results show that the exchange rate is strongly affected by prices in both markets. This again contrasts the findings of Grammig et al. (2005).

Panel B presents the results for the New Zealand stocks. Overall, the NZX is the dominant market for all stocks. However, this dominance is much more pronounced in the NZX. In the NZX, the information shares for NZX prices are almost $100 \%$ for all stocks. This indicates that within the NZX, the ASX serves as a pure satellite. When considering the ASX market, we observe that ASX prices are not dominant but do play an important role in terms of price discovery. Information shares for the ASX market are as high as $43.88 \%$ (ANZ).

The last column again shows the information shares of the different markets in the FX market. For all stocks we find a very high information share for the ASX prices, indicating that these prices are dominant in terms of price discovery in this market.

\subsection{Conditional Information Shares over Time}

Next we consider how these information shares have changed over time. Table 5 presents the results for the conditional information shares per year.

\section{INSERT TABLE 5 HERE}

In Panel A we present the results for the Australian stocks. First the information shares in the ASX are considered. Over time there appears to have been some shift in the information shares, but not in a particular direction. For two stocks (AMP and ANZ) the ASX information shares have decreased, while NZX information shares have increased. For the other two stocks the opposite is observed. The role of the exchange rate in the ASX is almost non-existent. The information shares in the NZX show a similar picture. For AMP and ANZ, the ASX information shares have decreased, while the NZX information shares increase, for the other two stocks ASX information shares have increased. Noteworthy though is that the exchange rate does 
play some role in this market, although it has only a marginal impact. The last part of Panel A shows the information shares for Australian domiciled stocks in the FX market. Our findings confirm those presented in Table 4, the exchange rate is not a purely exogenous process, but is affected by price shocks in both the ASX and the NZX. We do note some trend over time. For all stocks the ASX information share has decreased over time, whereas the NZX information share has increased. In 2005 the information shares for the different markets are, on average, about equal.

Panel B presents the results for the different information shares for NZX domiciled firms. First the results for the information shares in the ASX are presented. The results for changes in the information shares over time are again mixed. For two stocks (AIA and WHS) the ASX information has decreased over time, while the NZX information share has increased. The opposite again holds for the other stocks. Contrasting to the Australian domiciled stocks we find that the FX rate plays some role in the price discovery process of New Zealand domiciled stocks, although again its impact is marginal. Results are slightly different for the information shares in the NZX market. For almost all stocks (except for FBU) the ASX information share has increased, but in some cases only marginally. However, the NZX information share in its own market remains dominant. Further, the exchange rate plays almost no role in this market. Lastly, we present results for the information shares in the FX market. Although it was observed in Table 4 that price discovery in the FX market for New Zealand domiciled stocks is dominated by ASX prices, this dominance appears to be decreasing over time, and that the importance of the NZX price is increasing. This finding is in line with that presented for Australian domiciled stocks presented in panel A.

The results presented above again highlight the importance of the exchange rate in assessing price discovery among these markets. Whereas results in Table 3 suggest an increasing importance of the ASX for price discovery in both markets, we find that by incorporating the exchange rate, the increase in ASX information shares diminishes. Interestingly, we observe that over time the information share of the Australian prices in the exchange rate decreases, whereas the importance of the New Zealand prices increase. This could explain the observed increase in ASX information shares in Table 
3. Not including the exchange rate in the model could therefore lead to erroneous conclusions.

\section{Conclusion}

In this paper we examined price discovery for cross-listed stocks listed on both the ASX and the NZX. By computing information shares for the full sample period, in either a single currency or by following Grammig et al.'s (2005) approach, we confirm the findings presented in previous studies, which show dominance in terms of price discovery for the home market. An initial investigation into the change in information shares over time suggests that the information shares for the ASX are increasing for both Australian and New Zealand domiciled firms. However, when the exchange rate is incorporated into the model our findings change.

We firstly find that the determination of the exchange rate is not exogenous to the prices in the two markets. Shocks to the price in both ASX and NZX do have an impact on the exchange rate. Although this contrasts with the findings of Grammig et al. (2005) this can be explained by the fact that the AUD/NZD cross-rate is considered to be a "commodity currency" (Chen and Rogoff, 2003). Commodity currencies are strongly affected by changes in relative commodity prices, which in turn may be linked to overall stock price performance of these markets.

Secondly, we find that once the exchange rate is incorporated into the model, the increased importance of the ASX market over the NZX market diminishes considerably. This is due to the fact that the informational share of the ASX relative to the NZX in the foreign exchange market decreases. This finding has important implications for the study of price discovery of cross-listings in markets for which the exchange rate is not a fully exogenous process. 


\section{References}

Beveridge, S. and C.R. Nelson (1981), "A New Approach to the Decomposition of Econmic Time Series into Permanent and Transitory Components with Particular Attention to Measurement of the Business Cycle," Journal of Monetary Economics 7, 151-174.

Chen Y.-C. and K. Rogoff (2003), “Commodity Currencies,” Journal of International Economics 60, 133-160.

Ding, D., F. H. deB. Harris, S. Lau and T. McInish (1999), “An Investigation of Price Discovery in Informationally-Linked Markets: Equity Trading in Malaysia and Singapore,” Journal of Multinational Financial Management 9, 317-329.

Eun, C. S. and S. Sabherwal (2003), "Cross-Border Listing and Price Discovery: Evidence from US-Listed Canadian Stocks," Journal of Finance 58, 549-575.

Grammig, J., M. Melvin and C. Schlag (2005), "Internationally Cross-listed Stock Prices during Overlapping Trading Hours: Price Discovery and Exchange Rate Effects," Journal of Empirical Finance 12, 139 - 164.

Harris, F.H. deB., T. McInish, G. Shoesmith and R. Wood (1995), "Cointegration, Error Correction, and Price Discovery on Informationally Linked Security Markets," Journal of Financial and Quantitative Analysis 30, 563-579.

Harris, F.H. deB., T. McInish, and R. Wood (2002), "Security Price Adjustment across Exchanges: An Investigation of Common Factor Components for Dow Stocks," Journal of Financial Markets 5, 277-308.

Hasbrouck, J. (1995), “One Security, Many Markets: Determining the Contributions to Price Discovery", Journal of Finance 50, 1175-1199. 
Hupperets, E., and A. Menkveld (2002), "Intraday Analysis of Market Integration: Dutch Blue Chips Traded in Amsterdam and New York," Journal of Financial Markets 5, 57-82.

Johansen, S. (1988), "Statistical Analysis of Cointegrating Vectors", Journal of Economic Dynamics and Control 12, 231-254.

Kadapakkam, P., L. Misra, and Y. Tse (2003), "International Price Discovery for Emerging Stock Markets: Evidence from Indian GDRs," Review of Quantitative Finance and Accounting 21, 179-199.

Lieberman, O., U. Ben-Zion, and S. Hauser (1999), "A Characterization of the Price Behavior of International Dual Stocks: An Error Correction Approach," Journal of International Money and Finance 18, 289-304.

Lok, E. and P.S. Kalev (2006), “The Intraday Price Behaviour of Australian and New Zealand Cross-listed Stocks", International Review of Financial Analysis 15, 377397.

Menkveld, A.J., S.J. Koopman and A. Lucas (2006), "Modeling Round-the-Clock Price Discovery for Cross-Listed Stocks using State Space Methods," Journal of Business and Economic Statistics, forthcoming.

Pascual, R., B. Pascual-Fuster and F. Climent (2006), "Cross-Listing, Price Discovery and the Informativeness of the Trading Process," Journal of Financial Markets 9, 144-161.

Su, Q., and T. Chong (2006), "Determining the Contributions to Price Discovery for Chinese Cross-Listed Stocks", Pacific-Basin Finance Journal, forthcoming.

Xu, X., and H. Fung (2002), "Information Flows Across Markets: Evidence from China-backed Stocks Dual-Listed in Hong Kong and New York," The Financial Review 37, 563-588. 
Table 1: Summary Statistics

\begin{tabular}{|c|c|c|c|c|c|}
\hline & $\begin{array}{l}\text { Average } \\
\text { Price }\end{array}$ & $\begin{array}{l}\text { Average } \\
\text { Daily Trades }\end{array}$ & $\begin{array}{l}\text { Average } \\
\text { Daily Volume }\end{array}$ & $\begin{array}{l}\text { Average } \\
\text { Bid-ask Spread }\end{array}$ & $\begin{array}{l}\text { Average } \\
\text { Daily Quotes } \\
\end{array}$ \\
\hline \multicolumn{6}{|c|}{ Australian domiciled Firms } \\
\hline \multicolumn{6}{|c|}{ AMP } \\
\hline ASX & 8.66 & 1054 & $5,188,300$ & 0.0017 & 362 \\
\hline NZX & 10.98 & 17.0 & 36,102 & 0.1002 & 21.7 \\
\hline \multicolumn{6}{|l|}{ ANZ } \\
\hline ASX & 18.06 & 918 & $2,717,500$ & 0.0116 & 510 \\
\hline NZX & 22.67 & 4.83 & 9,437 & 0.2857 & 9.62 \\
\hline \multicolumn{6}{|l|}{ LNN } \\
\hline ASX & 5.74 & 93.2 & 495,830 & 0.0237 & 75.6 \\
\hline NZX & 6.28 & 6.71 & 73,455 & 0.0756 & 9.86 \\
\hline \multicolumn{6}{|l|}{ TLS } \\
\hline ASX & 4.76 & 1249 & $13,617,000$ & 0.0133 & 100 \\
\hline NZX & 5.81 & 10.6 & 77,087 & 0.0368 & 12.9 \\
\hline \multicolumn{6}{|c|}{ New Zealand domiciled Firms } \\
\hline \multicolumn{6}{|c|}{ AIA } \\
\hline ASX & 4.97 & 3.04 & 51,359 & 0.1317 & 5.96 \\
\hline NZX & 5.69 & 41.0 & 257,410 & 0.0198 & 26.3 \\
\hline \multicolumn{6}{|l|}{ FBU } \\
\hline ASX & 3.96 & 6.19 & 77,814 & 0.0666 & 9.75 \\
\hline NZX & 3.82 & 42.43 & 627,410 & 0.0157 & 24.8 \\
\hline \multicolumn{6}{|l|}{ TEL } \\
\hline ASX & 4.57 & 93.8 & $1,108,500$ & 0.0100 & 65.1 \\
\hline NZX & 5.16 & 115 & $3,264,000$ & 0.0133 & 60.5 \\
\hline \multicolumn{6}{|l|}{ TWR } \\
\hline ASX & 1.64 & 38.3 & 316,350 & 0.0177 & 15.3 \\
\hline NZX & 2.72 & 34.9 & 381,400 & 0.0156 & 18.4 \\
\hline \multicolumn{6}{|l|}{ WHS } \\
\hline ASX & 4.75 & 4.12 & 11,530 & 0.1249 & 5.66 \\
\hline $\mathrm{NZX}$ & 5.50 & 40.2 & 227,860 & 0.0230 & 26.4 \\
\hline
\end{tabular}


Table 2: Information Shares

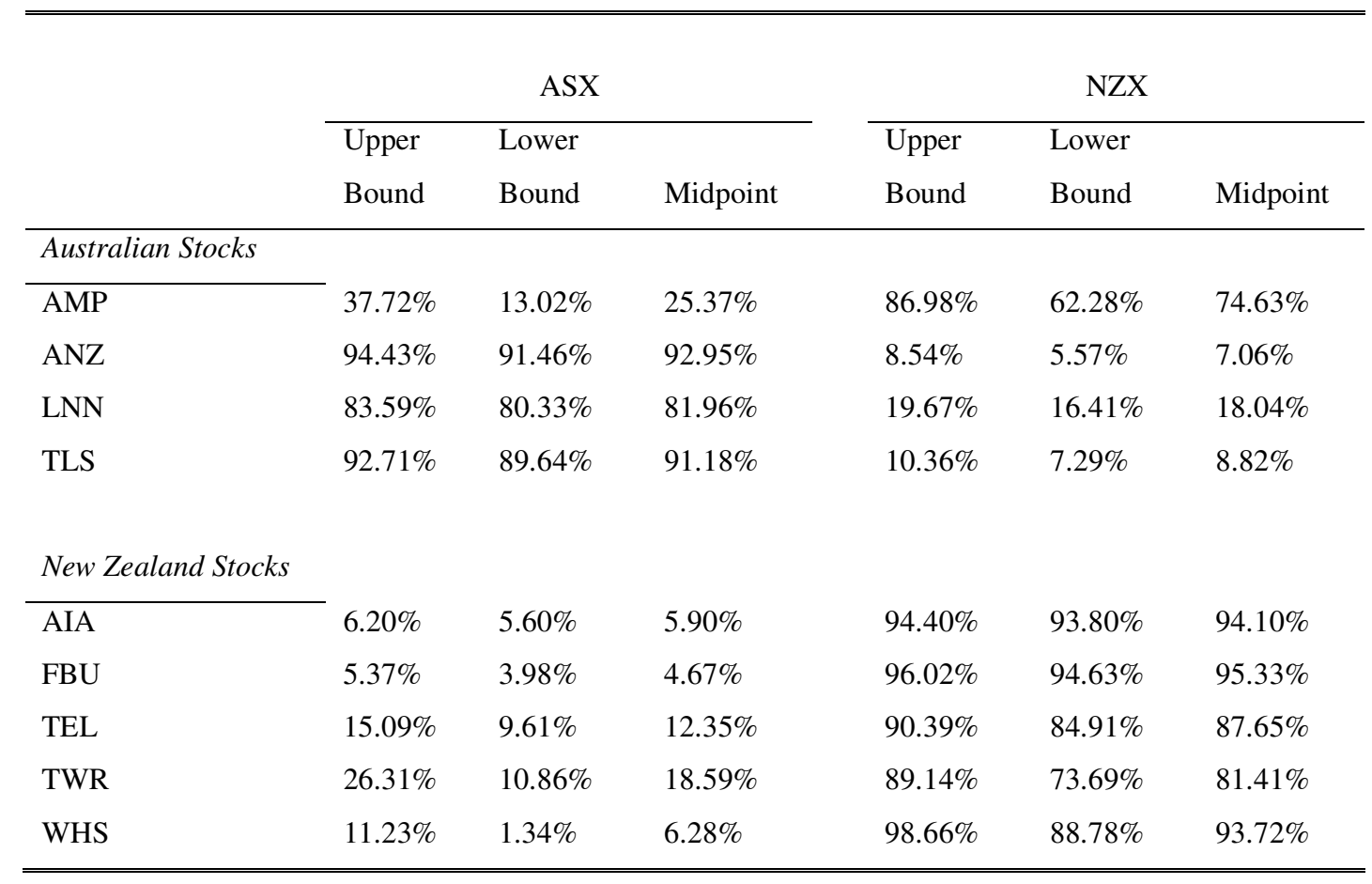


Table 3: Information Shares per Year

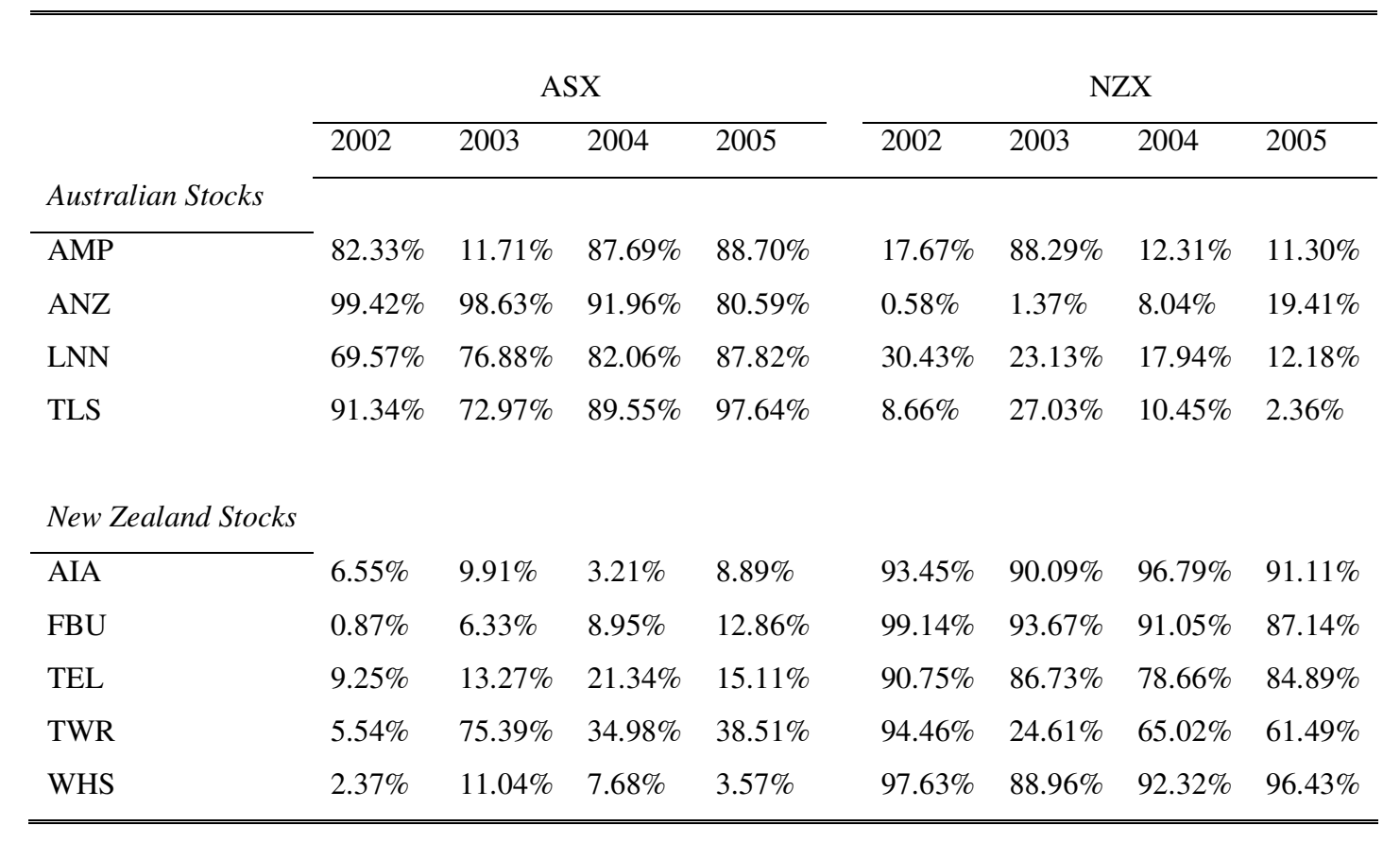


Table 4: Midpoints of Conditional Information Shares per Market.

\begin{tabular}{|c|c|c|c|c|}
\hline \multicolumn{5}{|c|}{ Panel A: Australian Domiciled } \\
\hline \multirow{2}{*}{ AMP } & \multirow[b]{2}{*}{$\begin{array}{l}\text { AS } \\
X\end{array}$} & ASX & $\mathrm{NZX}$ & FX \\
\hline & & $24.95 \%$ & $18.21 \%$ & $14.32 \%$ \\
\hline \multirow{5}{*}{ ANZ } & $\begin{array}{l}\mathrm{NZ} \\
\mathrm{X}\end{array}$ & $74.90 \%$ & $81.31 \%$ & $77.13 \%$ \\
\hline & FX & $0.15 \%$ & $0.48 \%$ & $8.55 \%$ \\
\hline & $\begin{array}{l}\text { AS } \\
X\end{array}$ & $79.84 \%$ & $53.91 \%$ & $20.12 \%$ \\
\hline & $\begin{array}{l}\mathrm{NZ} \\
\mathrm{X}\end{array}$ & $19.58 \%$ & $38.67 \%$ & $38.33 \%$ \\
\hline & FX & $0.57 \%$ & $7.42 \%$ & $41.56 \%$ \\
\hline \multirow[t]{3}{*}{ LNN } & $\begin{array}{l}\text { AS } \\
X\end{array}$ & $79.86 \%$ & $80.57 \%$ & $51.25 \%$ \\
\hline & $\begin{array}{l}\mathrm{NZ} \\
\mathrm{X}\end{array}$ & $20.14 \%$ & $12.35 \%$ & $27.97 \%$ \\
\hline & FX & $0.00 \%$ & $7.08 \%$ & $20.78 \%$ \\
\hline \multirow[t]{3}{*}{ TLS } & $\begin{array}{l}\text { AS } \\
X\end{array}$ & $99.38 \%$ & $86.28 \%$ & $28.56 \%$ \\
\hline & $\begin{array}{l}\mathrm{NZ} \\
\mathrm{X}\end{array}$ & $0.16 \%$ & $2.93 \%$ & $28.38 \%$ \\
\hline & $\mathrm{FX}$ & $0.47 \%$ & $10.79 \%$ & $43.05 \%$ \\
\hline \multicolumn{5}{|c|}{ Panel B: New Zealand Domiciled } \\
\hline \multirow{4}{*}{ AIA } & & ASX & $\mathrm{NZX}$ & FX \\
\hline & $\begin{array}{l}\text { AS } \\
X\end{array}$ & $43.88 \%$ & $1.47 \%$ & $90.46 \%$ \\
\hline & $\begin{array}{l}\mathrm{NZ} \\
\mathrm{X}\end{array}$ & $53.76 \%$ & $98.52 \%$ & $3.16 \%$ \\
\hline & FX & $2.36 \%$ & $0.00 \%$ & $6.37 \%$ \\
\hline \multirow[t]{3}{*}{ FBU } & $\begin{array}{l}\text { AS } \\
X\end{array}$ & $23.24 \%$ & $0.19 \%$ & $82.32 \%$ \\
\hline & $\begin{array}{l}\mathrm{NZ} \\
\mathrm{X}\end{array}$ & $72.62 \%$ & $99.70 \%$ & $4.78 \%$ \\
\hline & FX & $4.15 \%$ & $0.11 \%$ & $12.90 \%$ \\
\hline \multirow[t]{3}{*}{ TEL } & $\begin{array}{l}\text { AS } \\
X\end{array}$ & $27.78 \%$ & $4.79 \%$ & $64.24 \%$ \\
\hline & $\begin{array}{l}\mathrm{NZ} \\
\mathrm{X}\end{array}$ & $66.12 \%$ & $95.20 \%$ & $5.87 \%$ \\
\hline & FX & $6.10 \%$ & $0.01 \%$ & $29.90 \%$ \\
\hline \multirow[t]{3}{*}{ TWR } & $\begin{array}{l}\text { AS } \\
X\end{array}$ & $31.84 \%$ & $14.18 \%$ & $68.72 \%$ \\
\hline & $\begin{array}{l}\mathrm{NZ} \\
\mathrm{X}\end{array}$ & $66.92 \%$ & $85.79 \%$ & $18.96 \%$ \\
\hline & FX & $1.24 \%$ & $0.03 \%$ & $12.32 \%$ \\
\hline \multirow[t]{3}{*}{ WHS } & $\begin{array}{l}\text { AS } \\
X\end{array}$ & $17.41 \%$ & $3.49 \%$ & $58.97 \%$ \\
\hline & $\begin{array}{l}\mathrm{NZ} \\
\mathrm{X}\end{array}$ & $80.05 \%$ & $96.36 \%$ & $29.87 \%$ \\
\hline & $\mathrm{FX}$ & $2.55 \%$ & $0.15 \%$ & $11.15 \%$ \\
\hline
\end{tabular}


Table 5: Conditional Information Shares per market per year

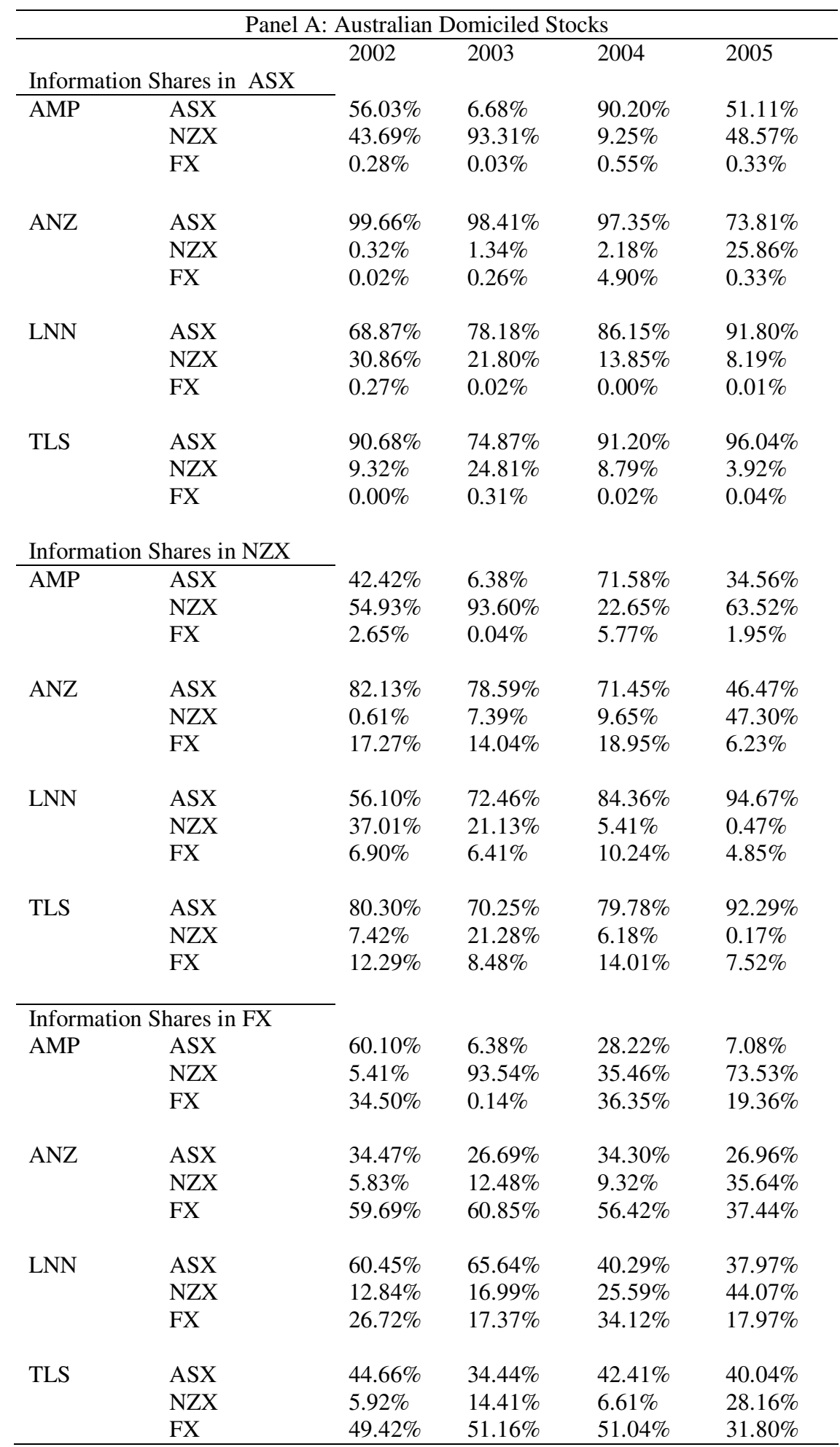




\begin{tabular}{|c|c|c|c|c|c|}
\hline \multicolumn{6}{|c|}{ Panel B: New Zealand Domiciled Stocks } \\
\hline & & 2002 & 2003 & 2004 & 2005 \\
\hline \multicolumn{6}{|c|}{ Information Shares in ASX } \\
\hline \multirow[t]{3}{*}{ AIA } & ASX & $58.76 \%$ & $18.47 \%$ & $17.61 \%$ & $24.01 \%$ \\
\hline & $\mathrm{NZX}$ & $39.69 \%$ & $73.80 \%$ & $74.53 \%$ & $73.59 \%$ \\
\hline & $\mathrm{FX}$ & $1.55 \%$ & $7.73 \%$ & $7.86 \%$ & $2.38 \%$ \\
\hline \multirow[t]{3}{*}{ FBU } & ASX & $16.33 \%$ & $2.12 \%$ & $20.59 \%$ & $24.82 \%$ \\
\hline & NZX & $76.91 \%$ & $90.90 \%$ & $73.81 \%$ & $72.18 \%$ \\
\hline & $\mathrm{FX}$ & $6.77 \%$ & $6.96 \%$ & $5.61 \%$ & $3.00 \%$ \\
\hline \multirow[t]{3}{*}{ TEL } & ASX & $26.56 \%$ & $28.74 \%$ & $35.54 \%$ & $30.15 \%$ \\
\hline & NZX & $66.78 \%$ & $65.66 \%$ & $57.41 \%$ & $63.51 \%$ \\
\hline & $\mathrm{FX}$ & $6.66 \%$ & $5.62 \%$ & $7.09 \%$ & $6.34 \%$ \\
\hline \multirow[t]{3}{*}{ TWR } & ASX & $14.40 \%$ & $56.00 \%$ & $44.47 \%$ & $43.24 \%$ \\
\hline & $\mathrm{NZX}$ & $82.97 \%$ & $43.18 \%$ & $54.34 \%$ & $56.36 \%$ \\
\hline & $\mathrm{FX}$ & $2.93 \%$ & $0.82 \%$ & $1.21 \%$ & $0.41 \%$ \\
\hline \multirow[t]{3}{*}{ WHS } & ASX & $25.60 \%$ & $24.84 \%$ & $27.39 \%$ & $22.28 \%$ \\
\hline & NZX & $65.99 \%$ & $73.29 \%$ & $67.80 \%$ & $75.86 \%$ \\
\hline & $\mathrm{FX}$ & $8.41 \%$ & $2.51 \%$ & $4.81 \%$ & $1.87 \%$ \\
\hline \multicolumn{6}{|c|}{ Information Shares in NZX } \\
\hline \multirow[t]{3}{*}{ AIA } & ASX & $3.27 \%$ & $0.05 \%$ & $0.71 \%$ & $3.47 \%$ \\
\hline & NZX & $96.73 \%$ & $99.94 \%$ & $99.27 \%$ & $96.53 \%$ \\
\hline & $\mathrm{FX}$ & $0.00 \%$ & $0.01 \%$ & $0.02 \%$ & $0.00 \%$ \\
\hline \multirow[t]{3}{*}{ FBU } & ASX & $11.35 \%$ & $1.80 \%$ & $1.76 \%$ & $4.78 \%$ \\
\hline & $\mathrm{NZX}$ & $88.12 \%$ & $98.08 \%$ & $98.22 \%$ & $95.22 \%$ \\
\hline & $\mathrm{FX}$ & $0.53 \%$ & $0.13 \%$ & $0.02 \%$ & $0.00 \%$ \\
\hline \multirow[t]{3}{*}{ TEL } & ASX & $2.34 \%$ & $5.84 \%$ & $12.22 \%$ & $8.39 \%$ \\
\hline & $\mathrm{NZX}$ & $97.66 \%$ & $93.94 \%$ & $86.94 \%$ & $91.50 \%$ \\
\hline & $\mathrm{FX}$ & $0.00 \%$ & $0.21 \%$ & $0.85 \%$ & $0.11 \%$ \\
\hline \multirow[t]{3}{*}{ TWR } & ASX & $4.90 \%$ & 31.20 & $24.91 \%$ & $28.18 \%$ \\
\hline & $\mathrm{NZX}$ & $94.85 \%$ & $68.28 \%$ & $74.13 \%$ & $71.00 \%$ \\
\hline & $\mathrm{FX}$ & $0.28 \%$ & $0.53 \%$ & $0.97 \%$ & $0.82 \%$ \\
\hline \multirow[t]{3}{*}{ WHS } & ASX & $0.11 \%$ & $8.87 \%$ & $1.47 \%$ & $2.24 \%$ \\
\hline & NZX & $99.89 \%$ & $90.73 \%$ & $98.47 \%$ & $97.74 \%$ \\
\hline & $\mathrm{FX}$ & $0.00 \%$ & $0.63 \%$ & $0.07 \%$ & $0.02 \%$ \\
\hline
\end{tabular}




\begin{tabular}{|c|c|c|c|c|c|}
\hline \multicolumn{6}{|c|}{ Panel B (Continued) } \\
\hline \multicolumn{6}{|c|}{ Information Shares in FX } \\
\hline \multirow[t]{3}{*}{ AIA } & ASX & $95.62 \%$ & $66.69 \%$ & $56.45 \%$ & $71.98 \%$ \\
\hline & NZX & $0.83 \%$ & $4.16 \%$ & $6.01 \%$ & $13.65 \%$ \\
\hline & FX & $3.55 \%$ & $29.15 \%$ & $37.55 \%$ & $14.38 \%$ \\
\hline \multirow[t]{3}{*}{ FBU } & ASX & $93.40 \%$ & $40.98 \%$ & $66.34 \%$ & $65.99 \%$ \\
\hline & NZX & $0.05 \%$ & $21.61 \%$ & $6.84 \%$ & $19.09 \%$ \\
\hline & $\mathrm{FX}$ & $6.55 \%$ & $37.41 \%$ & $26.83 \%$ & $14.93 \%$ \\
\hline \multirow[t]{3}{*}{ TEL } & ASX & $69.46 \%$ & $61.19 \%$ & $50.94 \%$ & $56.19 \%$ \\
\hline & NZX & $1.29 \%$ & $3.45 \%$ & $4.98 \%$ & $10.66 \%$ \\
\hline & FX & $29.27 \%$ & $35.44 \%$ & $44.19 \%$ & $33.18 \%$ \\
\hline \multirow[t]{3}{*}{ TWR } & ASX & $75.68 \%$ & $77.38 \%$ & $67.30 \%$ & $65.47 \%$ \\
\hline & NZX & $12.07 \%$ & $5.86 \%$ & $9.23 \%$ & $22.56 \%$ \\
\hline & $\mathrm{FX}$ & $12.74 \%$ & $16.79 \%$ & $23.57 \%$ & $12.02 \%$ \\
\hline \multirow[t]{3}{*}{ WHS } & ASX & $72.64 \%$ & $75.45 \%$ & $73.80 \%$ & $75.31 \%$ \\
\hline & NZX & $1.31 \%$ & $17.09 \%$ & $4.67 \%$ & $12.32 \%$ \\
\hline & FX & $26.05 \%$ & $8.84 \%$ & $21.54 \%$ & $12.38 \%$ \\
\hline
\end{tabular}


Figure 1: Impulse Response Functions

\section{Australian domiciled firms}
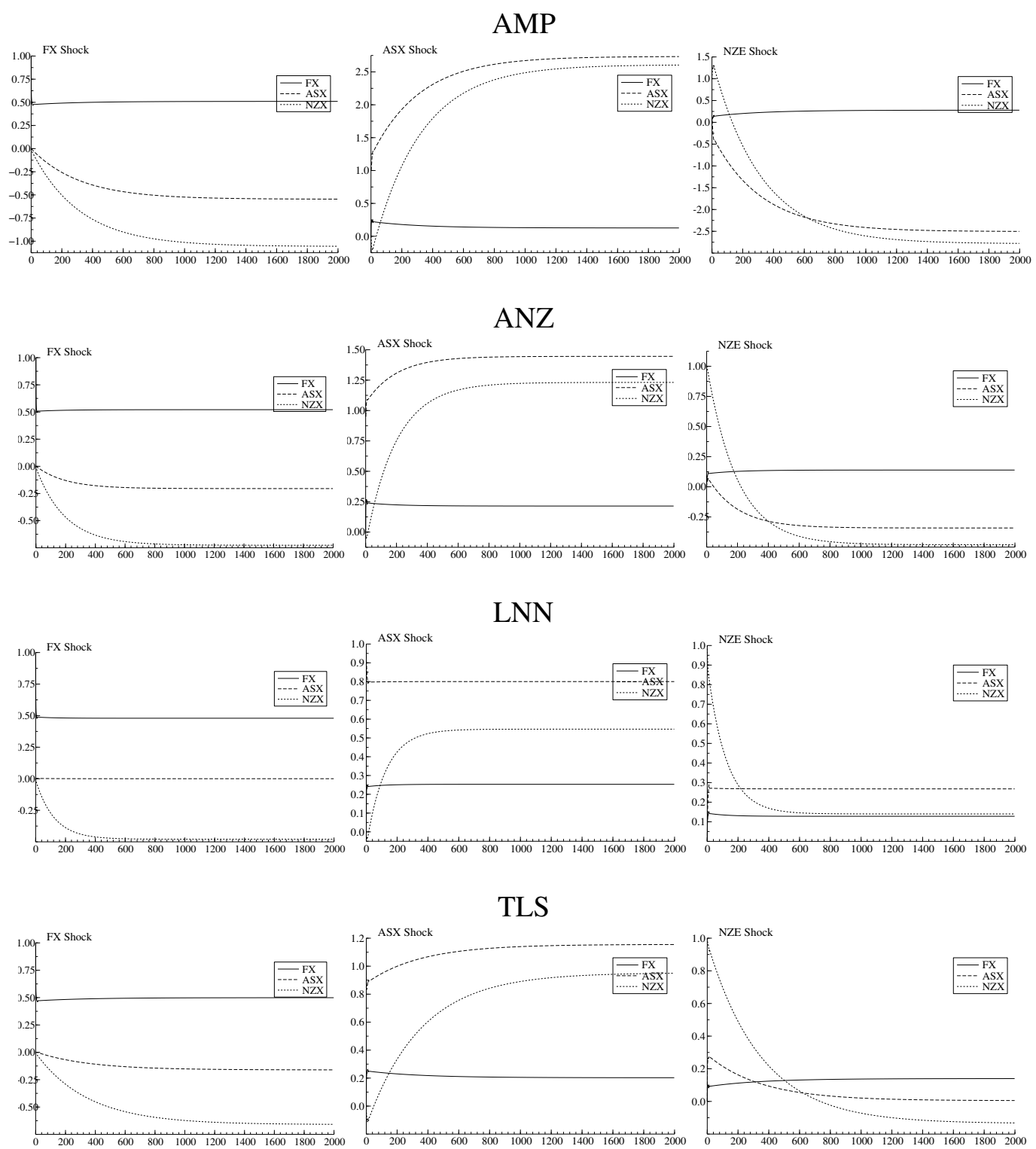


\section{New Zealand domiciled firms}
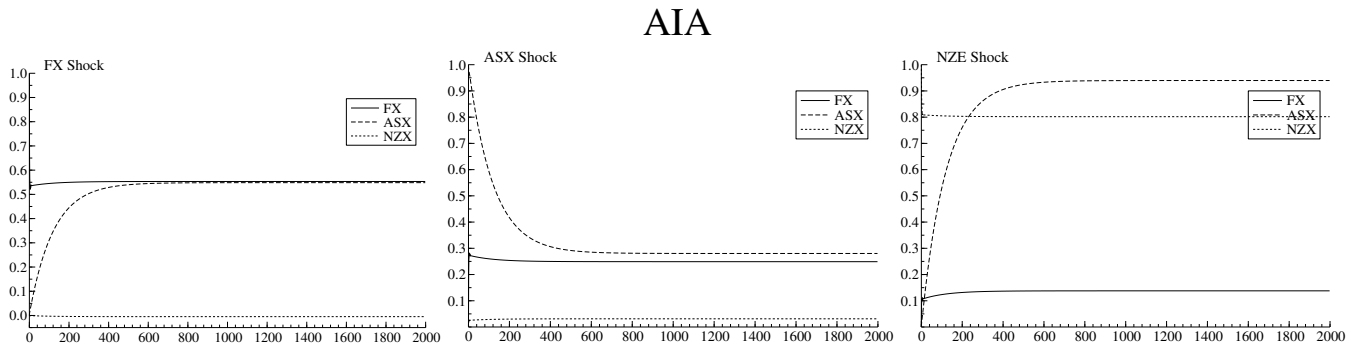

FBU

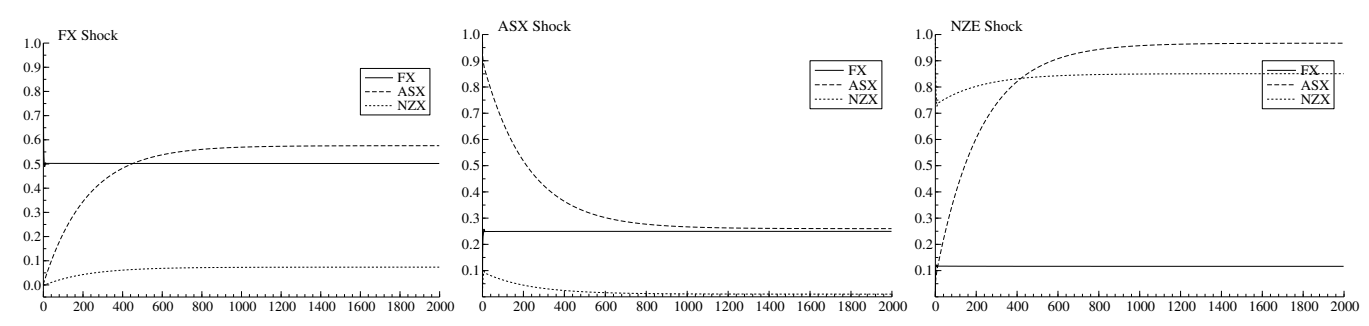

TEL

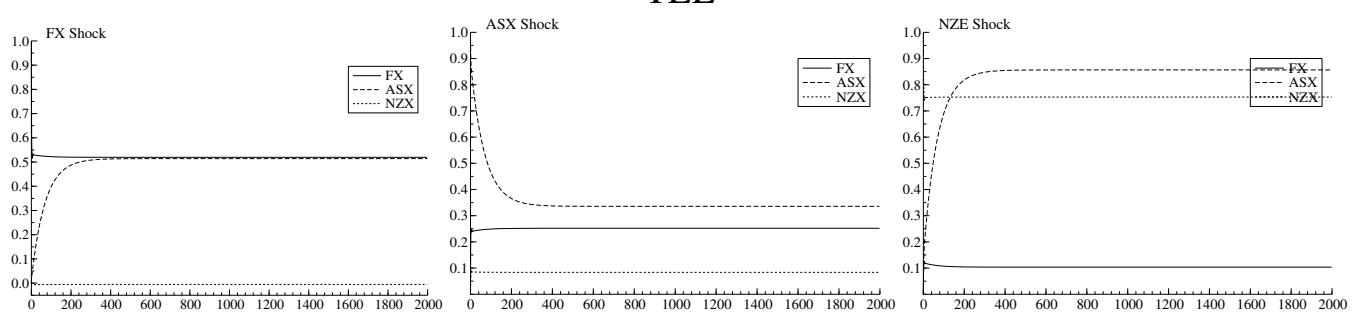

\section{TWR}
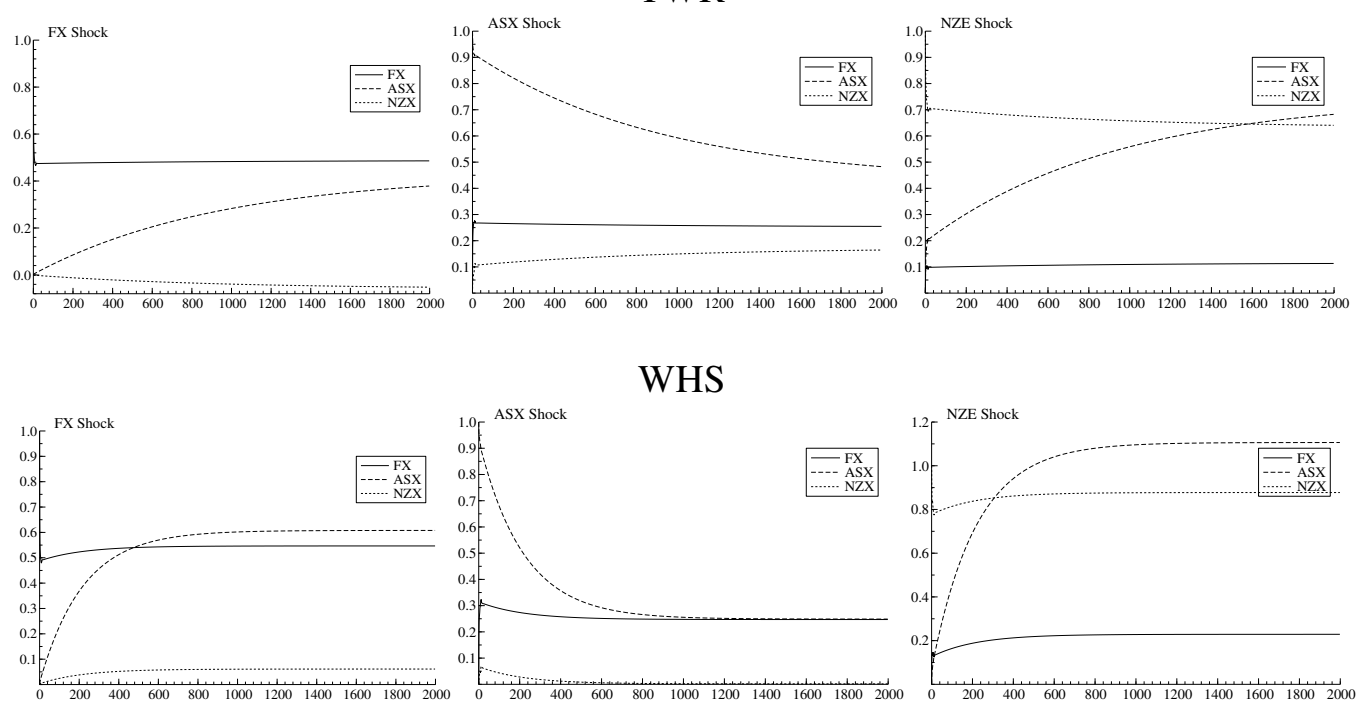